\title{
Astute Bus Identification System for the Visually Impaired
}

\author{
K. Suresh, Witteric Lourdesmarie Juliana, S. Aruneshvasan, D.B. Kishoredass
}

Department of Electrical and Electronics Engineering, Sri Manakula Vinayagar Engineering College, Puducherry 605107, India

Corresponding Author Email: suresh.kaliyamoorthy@gmail.com

https://doi.org/10.18280/mmc_c.802-403

Received: 1 February 2019

Accepted: 22 May 2019

\section{Keywords:}

visually impaired person, radio frequency identification, global positioning system, global system for mobile communication, arduino UNO

\begin{abstract}
Visually Impaired Person (VIP) encounters many difficulties while walking on the road, in finding the way, taking a bus and to undergo usual life-arena. To overcome the drawbacks of the present VIP navigation technologies, this paper presents a VIP navigation system based on Global Positioning System (GPS) and Global System for Mobile communication (GSM). The proposed system consists of key features like GPS (to identify the location of the bus) and GSM module (Sends message to VIP), Audio playback IC, Numeric keypad using Microcontroller. It finds the latitude, longitude and distance which are calibrated for the specified routes. The desired bus that the VIP wants to travel is notified to him/her. As the VIP presses a button on the User module the distance of the bus is sent to the VIP. This proposed system can be applied in real-time; the VIP can utilize the transportation in a safe manner.
\end{abstract}

\section{INTRODUCTION}

Of the 7.6 billion, people that makes up the population the world, 36 million are visually impaired and it is expected that this number will rise to 115 million by 2050 [1]. Yet, the complications in the navigation or the routing for the blind are complex and bothersome, especially when they wish to walk down the streets or to voyage to distant places by making use of the public transport utilities. For a VIP, accomplishments such as reading traffic signals and street signs can be an extremely challenging task. To overcome the abovementioned challenges, a VIP might use walking canes, a guide dog or a sighted guide. These alternatives, collectively known as "Assistive devices" can be of much help to the VIPs but are less effective in most instances.

Nowadays, numerous systems that aid VIPs are developed or existing systems are improvised to do so. This system ensured to be advantageous in creating a prospect for the VIP to utilize the public means of transportation in a way easing their means of commode and making it more convenient for them. The VIPs can reach to somewhere that usually is a crisis for a VIP to reach. Yet weaknesses do exist, some parts might be upgraded and designed to gain additional efficacy in the real time model. By making use of the proposed system, a VIP can search the destination which they want to go and could recognize exactly the distance between the buses and the VIP.

Agrawal et al. [2] proposed a system that sheds the light on the field of transportation to improve the life quality of the VIPs. Quoc et al. [3] proposed the U-bus system design based on WSN for blind people. This system has two main parts. The first part is a blind people recognition. Another part is communication between a bus and bus station. Mounika et al. [4] proposed a Wireless based bus system. Blind people in the bus station are provided with a ZigBee unit. Aswathy et al. [5] (2016), proposed system a bus detection prototype using RFID for blind. The RFID has the potential to be useful that aids with further standardization of RFID tags and improvement of current RFID readers. Mehra et al. [5] modeled a radiofrequency based system that helps the user to identify the route number and then it enables the user to board the bus using the auditory cues from the entrance of the bus. El Alamy et al. [7] proposed a system that will allow VIPs to safely catch buses with the help of an audio device and a tactile interface through a wireless communication system (Wi-Fi) between the transmitters and the receiver. Dharini et al. [8] developed a system for the visually challenged people, old age people \& uneducated people to identify their bus through voice alert system using 8051 Microcontroller. Ding et al. [9] presented a blind navigation system based on RFID, wireless and mobile communications technologies. The system consists of RFID tag, portable reader which can be integrated into the blind cane, mobile phone, and Call Center and center information servers. Gorantla et al. [10] developed the solar assisted three-wheeler auto rickshaws and also to implement an energy management strategy that is suitable for Indian city-driving pattern and driving requirement's setup. Pal and Pali [11] focused research work for free passage to escape of ambulance from the traffic lights or streets means the ambulance would not stop in the traffic jams. This can be made possible using VANET-LTE advanced technology.

As the population grows, the number of VIPs has increased successively. At present, statistic showed that 285 million people are visually impaired worldwide: 39 million are blind. Many papers have been published and more research work has been done on this subject, this proposed model presents an all new simple approach towards the design. In the course of time, many electronic devices have already been developed and implemented in some areas to assist the VIPs like Sonic Guide, Mowat Sensor, Laser Cane and Navbelt. But all of them are to assist them while pedestrian crossing and there hasn't been developed any successful device to assist them boarding a bus.

The main contribution and scope of the proposed model is 
to develop a low-cost system that assists the visually impaired without the help of a sighted person. The main objective of this research work is to provide talk-back assistance to the VIPs. Current navigation device for the visually impaired focus on traveling from one location to another, from the study of literature, it is understood that there is a need for the VIPs to select a suitable bus from a number of buses available for them. Hence, we have proposed a bus identification system favoring the VIPs regarding their means of commode. Using the GSM Technology, this can be made possible.

Our aim is to design a hardware implementation of a bus identification system to aid the VIPs to utilize the public transportation facilities to help them to participate fully in society, access facilities and services. Paper is organized is as follows, Section 1 explains about the introduction of the proposed system. Section 2 describes our proposed bus identification system. Components used in the proposed work are described in Section 3. Section 4 describes about the results and discussion of the proposed system. Section 6 illustrates the conclusion of the paper.

\section{PROPOSED BUS IDENTIFICATION SYSTEM FOR THE VIP}

This proposed model consists of two modules: a bus module which is fixed on the bus and a user module which is with the VIP. The VIP is considered to be the user in the proposed model. User module consists of a GPS, GSM, Audio Playback Board, numeric keypad and Arduino Rev3 Microcontroller. A bus module consists of LCD interfaced with GPS and GSM modules. The location of the VIP is displayed in the LCD. Using the latitude and longitude coordinates of both user and bus the respective distance is calculated using Arduino coding.

VIP gets to select from the list of choices provided. It can be done by pressing the respective button on the numeric keypad or the sequence of push buttons provided. Once the choice is confirmed, the location of the user (which is tracked by GPS module) is sent to the bus module at the corresponding bus via GSM communication technology.

Through the Microcontroller source code modification, the distance is calculated by using location of both user module and bus module. It can be obtained from the respective GPS modules. Employing the GSM Technology for communication, this distance calculated is sent to the user module. The received message will be played using voice playback board at the user module. As stated above, the proposed model consists of two separate modules. The block diagram and the structure of the modules are explained in this section. The following section provides the details of the transmitter and receiver sections with the respective block diagram and its relevant explanation.

\subsection{Existing methods of bus identification system}

The existing system for bus identification for the visually impaired uses RFID transponders that are placed at the bus stop that transmits the information about the route numbers of the bus approaching, thus this system does not allow the user to choose between multiple buses standing at the bus stop and also, boarding to bus, according to the requisition remains unresolved. The major drawback of the existing system is that the selection of a bus the user wants; to choose from several buses is not provided.
The main disadvantages of the existing system are,

- Non-availability of sales, marketing or servicing in developing countries

- Inability to board a desired bus, since multiple buses arrive and line up arbitrarily at random positions at bus stops

- Route number displays on the front top panel of the bus, makes it difficult for a VIP to identify since there are no audio cues

- Dependency of a VIP on fellow travelers.

\subsection{Complete block diagram of the proposed model}

The overall block diagram of the proposed model of the bus identification system for the VIP is given in the Fig.1. The block diagram consists of two modules 1) User module and 2) Bus module. The user module consists of Arduino UNO, numeric keypad, Audio playback module APR 33A3, GSM800c, GPS 28ML. Initially, the VIP has to arrive at the bus stop with his module setup in order to track the distance of his respective desired bus. After the GPS and GSM signal is received, the VIP selects the required bus number by using the numeric keypad and voice playback module.

When GSM receives power, the blinking rate of the LED at the module is fast and after receiving the signal in the GSM, the blinking rate of the LED reduces to twice per second. Through voice playback module the signal received message is played to the VIP, along with the list of buses. The VIP selects the required bus number. Through the GPS module location of the VIP is tracked by using the Arduino code and location is sent to the bus module by using the GSM module. A bus module consists of an LCD, Arduino UNO, GSM800c, GPS 28ML. When GSM receives power, the blinking rate of the LED at the module is fast and after receiving the signal in the GSM, the blinking rate of the LED reduces to twice per second.
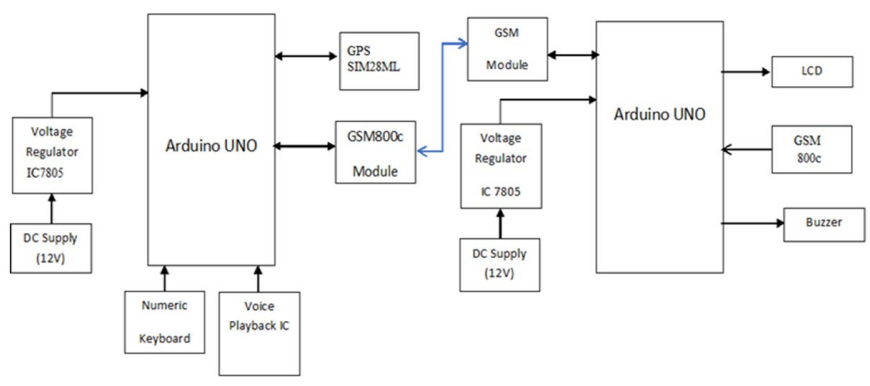

Figure 1. Block diagram of the proposed bus identification system

In the bus module, the location of the bus is tracked and after receiving the location of the VIP, the location of the VIP is displayed on the LCD. The distance is calculated by using the Arduino coding and via GSM distance is sent to the user module, through the voice playback IC, distance of the bus is sent to the VIP. Distance of the bus is indicated to the VIP by the voice playback module.

\subsubsection{Transmitter section (User module)}

This section deals with the block diagram of user module, which is placed with the VIP. The user module consists of a numeric keypad which is basically an assembly of push buttons made for easy access of the VIPs. With the aim of choosing from the choices of buses available in the given area, 
the VIP must select a push button corresponding to the choice that has to be made at the numeric keypad. Prior to the bus selection, the VIP receives an audio of the list of available buses. It is provided using the Audio playback module in the user module. It serves to be the easiest way of providing input at the user module. The GSM is a cellular technology used for transmitting location voice and data from the user module to the bus module. GPS stands for GPS provides the coordinates of the location of the module. The location from the GPS is sent to the bus module. Audio playback module consists of voice recording and playback system which is used to play the distance of the bus to the VIP. The block diagram of the user module or the Transmitter Section (User module) is shown in the Figure 2.

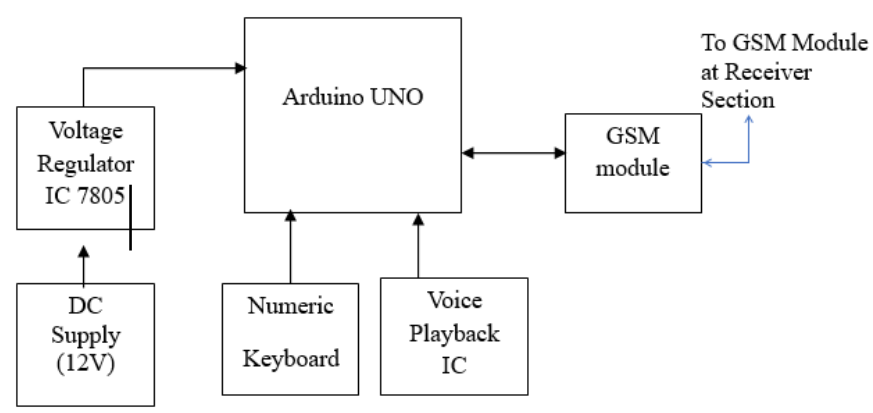

Figure 2. Block diagram of the user module

\subsubsection{Receiver section (Bus module)}

This section deals with the block diagram of bus module, which is located with the bus driver on the bus. Figure 3 gives the circuit diagram of bus module, which consists of an LCD, a GPS and a GSM as its main components.

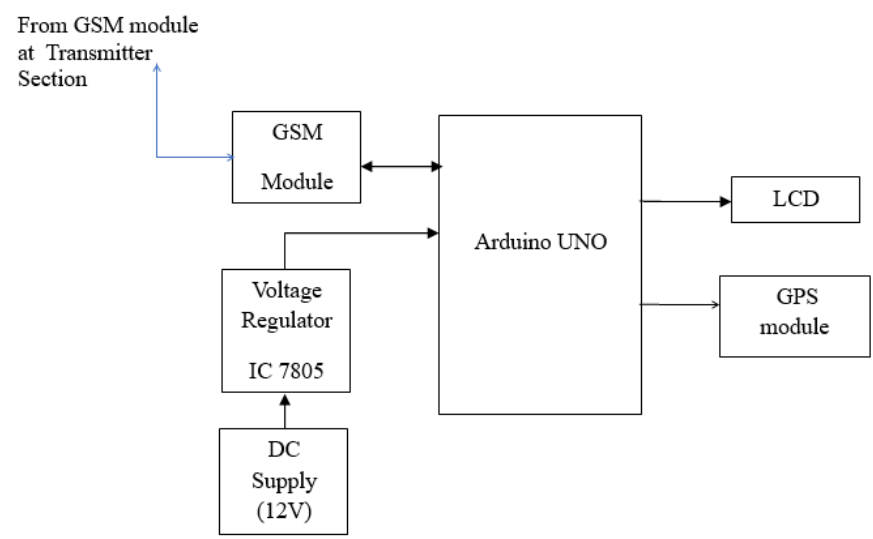

Figure 3. Block diagram of the bus model

LCD is used to display the location of the VIP. The GSM is a cellular technology used for transmitting location coordinates and data from the bus module to the user module. GPS stands for GPS provides the coordinates of the location of the module. In the bus module, location of the bus is tracked. This location of the VIP is received from the user module through the GSM technology. After receiving the location of the VIP, the distance is calculated using Equations (5) and (6).

\subsubsection{Description of the Bus module}

A bus module has power supply circuit, GSM, GPS, LCD display. From the power supply circuit to $5 \mathrm{~V}$ power is stepped down and given to the Arduino, In which Rx pin of GSM and $3^{\text {rd }}$ pin of the Arduino is connected and Tx pin of the GSM is connected to the digital $8^{\text {th }}$ pin of the Arduino. The Rx pin of the GPS module is connected to the Rx pin of the Arduino and similarly Tx pin of the Arduino is connected to the Tx pin of the Arduino. The LCD connection is established by using the $\left(7^{\text {th }}, 8^{\text {th }}, 9^{\text {th }}, 10^{\text {th }}, 11^{\text {th }}, 12^{\text {th }}\right)$ pins of the Arduino, to display the GPS location. In the bus module, the location of the VIP is tracked and after receiving the location of the VIP, the location of the VIP is displayed in the LCD.

\subsubsection{Description of the User module}

User module consists of power supply circuit, GSM, Voice Playback IC, speaker, GPS. From the power supply circuit to $5 \mathrm{~V}$ power is stepped down and given to the Arduino, In which Rx pin of GSM and $5^{\text {th }}$ pin of the Arduino is connected and Tx pin of the GSM is connected to the digital $6^{\text {th }}$ pin of the Arduino. The Rx pin of the GPS module is connected to the $\mathrm{Rx}$ pin of the Arduino and in the same way Tx pin of the Arduino is connected to the Tx pin of the Arduino. Voice playback connection is established by using the $\left(10^{\text {th }}, 11^{\text {th }}, 12\right.$ th $13^{\text {th }}$ ) pins of the Arduino to display the GPS location. By means of the numeric keypad and Audio Playback IC the VIP can select the required bus number.

Figure 4 shows the flowchart of the proposed bus identification method. The input from the user, their latitude and longitude is assumed as lat 1 and long 1 respectively. It considers the coordinates of the bus as lat 2 and long 2 . Initially, the GPS connectivity is checked which can be indicated by a blinking once in three seconds. Once the GPS connectivity is done, the input $i$ is read from the user. If $i$ is equal to any of the desired bus then the latitude and longitude of the user is sent to the respective VIP through GSM.

The location of the user is tracked using the GPS module. When the bus module receives the data from the user it calculates the distance between the bus (coordinates of the bus are also tracked by another GPS module) and the user. This difference between the two is calculated using "Haversine Formula". When the user press push button, the distance is sent to the user module via GSM, it is then conveyed to the VIP through speaker fitted in the user module. Furthermore, the coordinates of the bus and the user is same it will send the message as "bus has arrived". For additional information, the VIP has to press the push button again.

Arduino Microcontroller is used to control the entire activities of the proposed bus identification system. The advantages of the Microcontroller are listed below:

- Inexpensive/User friendly, Cross-platform.

- Simple and clear programming environment.

- Open source and extensible software and hardware.

\section{DETAILS OF HARDWARE}

Various components which are used for designing the Hardware part is discussed in this section.

\subsection{GSM module}

A GSM modem is a device which can be either a mobile phone or a modem device that can be used to make a computer, or any other processor communicate over a network. A GSM modem requires a SIM card to be operated and operates over a network range subscribed by the network operator. It can be connected to a computer through serial, USB or Bluetooth connection. 


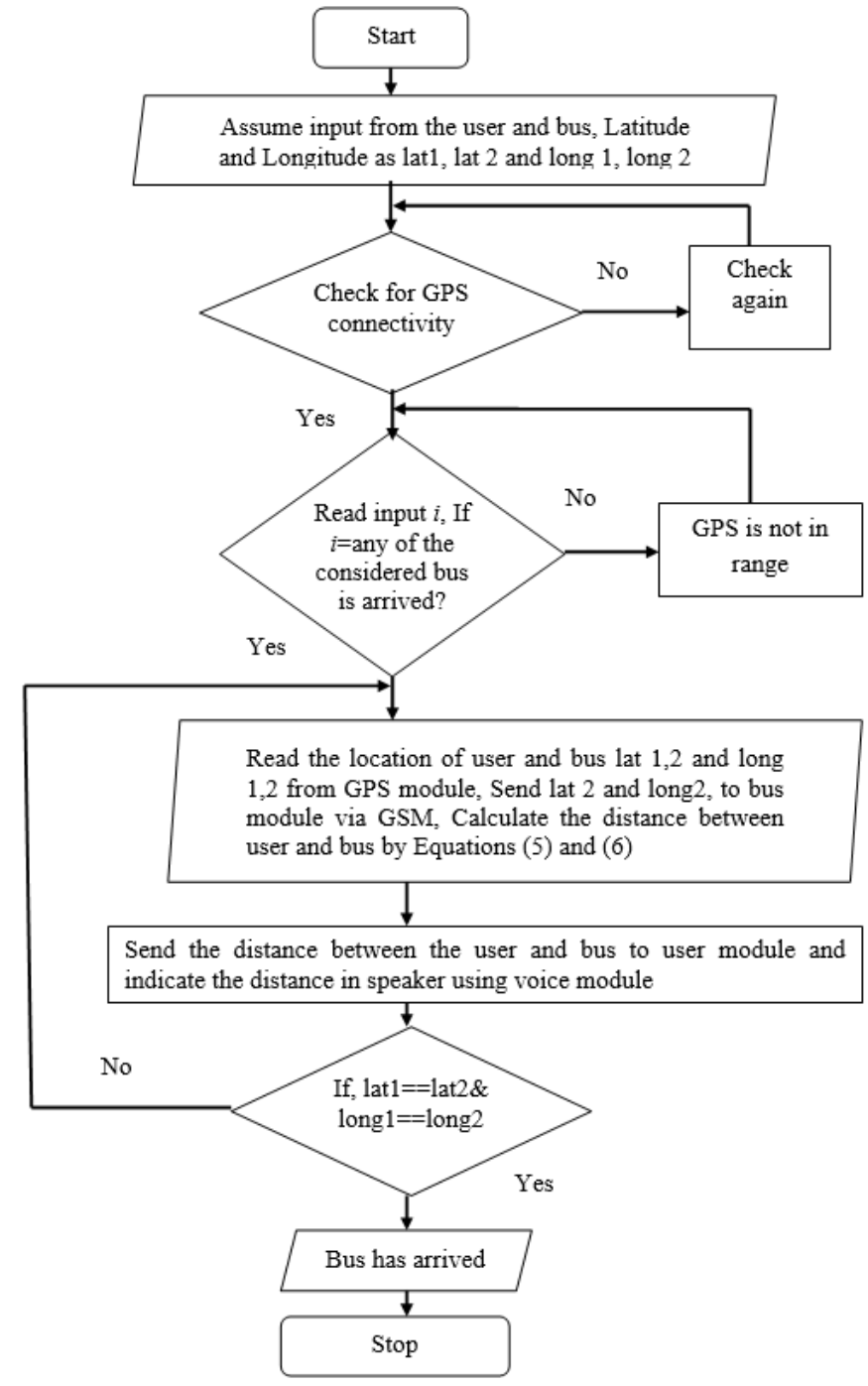

Figure 4. Flow chart of the decision tree

\subsection{GPS module}

The GPS is a space-based GNSS that provides reliable location and timely information in all weather and at all times and anywhere on or near the Earth when and where there is an unobstructed line of sight to four or more GPS satellites.

\subsection{Audio playback board-PR33A IC}

Today's consumers demand the best in audio/voice signals. They want crystal-clear sound wherever they are in whatever format they want to use. The aPR33A series are powerful audio processor along with the high performance audio, ADCs and DACs.

\subsection{ARDUINO-ATmega328pu}

The Arduino UNO is a Microcontroller board based on the ATmega328pu. It has 14 digital input/output pins of which 5 can be used as PWM outputs, 6 analog inputs, 4 UARTs (hardware serial ports), a $16 \mathrm{MHz}$ crystal oscillator, a USB connection, a power jack, an ICSP header, and a reset button. The Microcontroller is connected to a computer with a USB cable and AC-to-DC adapter / battery. The Arduino UNO can be programmed with the Arduino software.

\section{RESULTS AND DISCUSSION}

In real time our proposed model may be implemented in residential places like houses, flats, apartments, etc., and commercial places like hotels, hospitals, bus stands etc., with GPS connectivity. We have tested the proposed model working condition in two routes in India.

\subsection{Implementation of the proposed model}

In this proposed model, we have two modules such as user module (transmitter section) and bus module (receiver section). In the user module, we have placed an audio playback board APR33A3 IC in the user module that is used for VIP to communicate with the concerned bus driver. This voice playback IC is integrated with a speaker which gives an output like location of the bus at any time the user needs.

We also have a GPS module (GPS SIM28ML) which is used to track the location of the user. Two GSM modules (GSM SIM800C) are used in our proposed model, one at the user module and the other at the bus module. The GSM in the user module will send the location of the user to the corresponding bus module.

The received location is then compared with the current location of bus and the distance between the user and bus is calculated using Equations (5) and (6). This distance is then sent to the user and is this information is delivered to him/her through audio signal. In our proposed model, we have used the Arduino 1.8.5 version for coding and testing purposes. There are two program codes are used i.e. user module and bus module. These program codes are developed in the IDE.

This text-editor-like program is used to write the code for our proposed model. The open source Arduino software is easy to write code and upload it to the board. For the proposed system to work, we have used the Arduino software.

\subsubsection{Power supply circuit}

Figure 5 represents the power supply circuitry of the proposed model. Except for the GPS module, all the other components require a power supply of $5 \mathrm{~V}$ in common. To provide the input power supply to the components, a bridge rectifier circuit with a step down transformer and a voltage regulator is used. Equations (1)-(4) are used for design calculation of the proposed system. The design calculations for the power supply circuit are as follows:

Design Calculation of the power supply circuit components:

\section{IC 7812:}

$$
\begin{gathered}
I_{\text {out }}=1.5 \mathrm{~A}, t=10 \mathrm{~ms}, \\
V_{\mathrm{rms}}=12 \sqrt{2}=12 X 1.414=16.97 \mathrm{~V} \\
V=V_{\text {rms }}-\text { ripple voltage }=16.97-1.4=15.57 \mathrm{~V}
\end{gathered}
$$

$C=\left(I^{*} t\right) / V=\left(1.5 X 10 X 10^{-3}\right) / 15.57=963.39 \mu F \sim=1000 \mu F$

IC 7805:

$$
\begin{gathered}
I_{\text {out }}=1.2 \mathrm{~A}, t=10 \mathrm{~ms} \\
V_{\text {rms }}=5 \sqrt{2}=5 \times 1.414=6.414 \mathrm{~V} \\
V=V_{r m s}-\text { ripple voltage }=6.414-1.4=5.67 \mathrm{~V} \\
C=(I \mathrm{Xt}) / V=\left(1.2 \mathrm{X} 10 \mathrm{X} 10^{-3}\right) / 5.67=211 \mu F \sim=220 \mu \mathrm{F}
\end{gathered}
$$


where, $V$ is the output voltage in Volts, $I$ is the current in the circuit in Amperes, $t$ is the time corresponding to the capacitance in milliseconds, $C$ is the capacitance in microfarads.

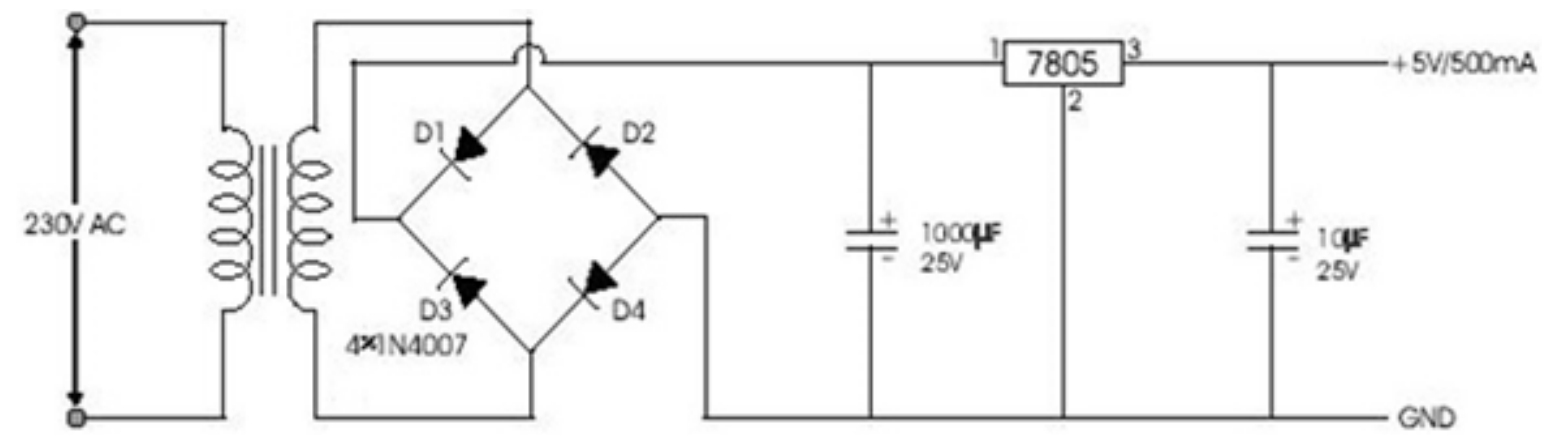

Figure 5. Power supply circuit of the proposed model

\subsection{Complete working model for Bus Identification System for the VIP}

The proposed hardware model consists of: a bus module and a user module. User module contains of a GPS, GSM, Audio Playback Board, Numeric keypad and Arduino Rev3 Microcontroller. A bus module includes GPS and GSM modules. Arduino coding is used to find the latitude and longitude coordinates of user and bus, the respective distance is information of the bus is given to the VIP. Schematic diagram of the proposed system is shown in Figure 6.

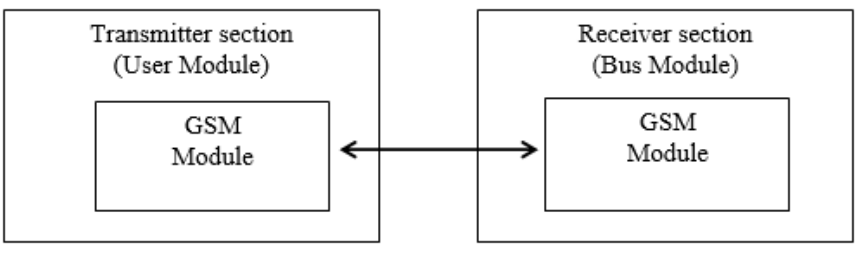

Figure 6. General schematic diagram of the proposed model

It gives the general overview of our proposed research work. Through GSM technology communication between transmitter and receiver section is established. The GSM is a digital mobile telephony system that is extensively used in many parts of the world. This is much easier and faster to deal with. The SMS is part of the GSM specification and allows short text messages to be sent or received also provides security through data encryption.

The distance is calculated between the user module and bus module. Employing the GSM technology for communication, this calculated distance is sent to the User module. The message will be played using audio playback board at the User module. For a majority of the VIPs, public transport is the only viable mobility option to seek education, work and social connectivity. The VIPs live in restrained environments, they have the difficulty to sense the events around them. It reduces their activities in several fields, such as education and transportation since they depend only on their own intuition. The VIP can easily travel from one place to another independently.

\subsection{Output of the proposed model}

The proposed method has been tested on two routes in India. The field trials were conducted on two college buses running on a major routes in Puducherry-Madagadipet-
Villupuram(India). In this case study, we have recorded, analyzed and presented the observations of the results. The routes are considered: Puducherry to Madagadipet (Puducherry,TamilNadu/India) and Villupuram to Madagadipet. We have calculated the distance of the bus by taking the latitude and longitude of the four places like Villianur, Kandamangalam, Thirubuvanai and Madagadipet in the Case Study 1.

Moreover, we have calculated the distance of the bus by taking the latitude and longitude of the four places like Mandhakarai, Koliyanur, Vallavanur and Madagadipet (Puducherry, TamilNadu/India) in the Case Study 2. Figure 7 shows the output of the bus module and the user module.

\subsection{4, 79.6365661621 Latitude lo...}

\section{latlong.net}

Figure 7. Output of the Bus module and User module

The output of the bus module is obtained in the form of a SMS that consists of location coordinates (latitude and longitude position) of the module. Figure 7 represents output of the case study, latitude and longitude of the bus, which is received as a SMS. We have received the text message by using distance formula and Arduino coding.

\subsubsection{Distance calculation}

The distance between two locations whose latitude and longitude [11] are known can be calculated using the Equations (5) and (6) which is commonly known as the Haversine formula. This formula calculates the shortest distance between two points on a sphere using their latitudes and longitudes measured along the surface. It is mainly used for navigation purpose.

$$
\begin{gathered}
a=\operatorname{pow}(\sin ((\text { end_lat }- \text { stlat }) / 2), 2)+\cos (\text { stlat }) \\
* \cos (\text { end_lat }) \\
* \operatorname{pow}(\sin ((\text { end_long }- \text { stlong }) / 2), 2) \\
\text { dist }=\text { radius_of_earth } * 2 \\
\quad * a \tan 2(\operatorname{sqrt}(a), \operatorname{sqrt}(1-a))
\end{gathered}
$$

where, dist is the distance between two points, lat, long are the 
latitudes, longitudes of the respective places respectively, longitude radius of earth $(6371 \mathrm{~km})$.

Figure 8 shows the distance calculation method between two destinations. With reference to the link, the distance is calculated between the bus and the VIP [12]. By considering Madagadipet as the destination distance of the bus, the distance is found and it is sent to the VIP. For example, suppose the bus is at Villianur, respective distance is approximately $13 \mathrm{~km}$ from Madagadipet. In this proposed work, important process has been done for the software design to control the proposed system. Initially, the file is created in the Arduino software. Subsequently, software code is used to compile and upload the code and test the various conditions of the proposed method.

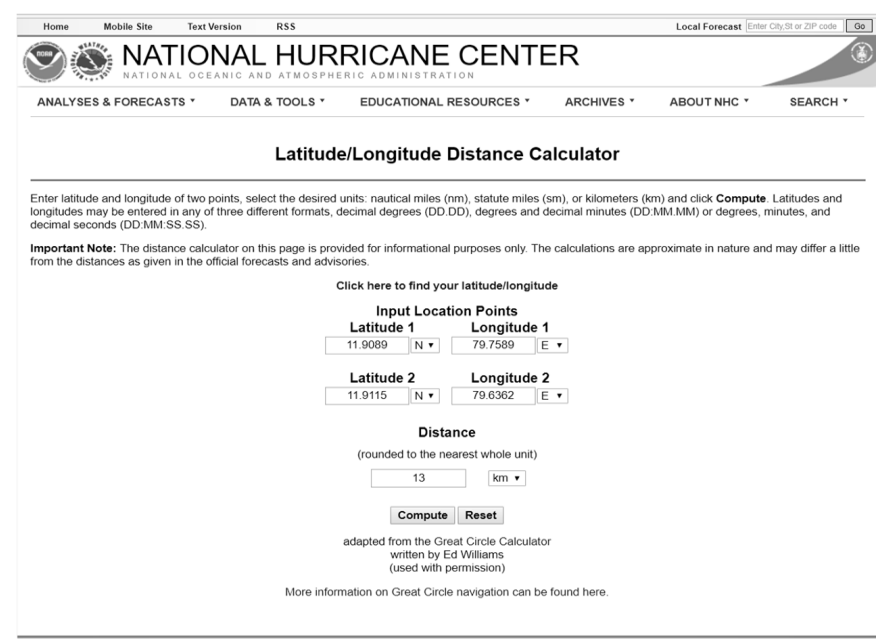

Figure 8. Distance calculation between two destinations

\subsection{Case study 1}

In this section, the distance between the bus and the VIP is found by considering the latitude and longitude of the four places like Villianur, Kandamangalam, Thirubuvanai and Madagadipet. Table 1 shows the locations which are identified by the proposed model for case study 1 .

Table 1. Output of the proposed model for case study 1

\begin{tabular}{ccccc}
\hline S.No & Place & Latitude & Longitude & Distance \\
\hline 1 & Villianur & $11.9089 \mathrm{~N}$ & $79.7589 \mathrm{E}$ & $13 \mathrm{~km}$ \\
2 & Kandamangalam & $11.9133 \mathrm{~N}$ & $79.6867 \mathrm{E}$ & $5 \mathrm{~km}$ \\
3 & Thirubuvanai & $11.9232 \mathrm{~N}$ & $79.6474 \mathrm{E}$ & $2 \mathrm{~km}$ \\
\hline
\end{tabular}

From the Table 1, it is considered that the bus is approaching the destination Madagadipet from Puducherry. We found the distance of the bus by taking the latitude and longitude of the four places like Villianur, Kandamangalam, Thirubuvanai and Madagadipet. The latitude and longitude coordinates of Madagadipet are given by $11.9115^{\circ} \mathrm{N}, 79.6362^{\circ}$ E respectively. By considering Madagadipet as the destination distance of the bus, the distance location of the bus is computed. This information is sent to the VIP. Hence, the VIP know the bus details and how far it away from him/her. For paradigm, suppose the bus is at Villianur, the distance of the bus from the Madagadipet is approximately $13 \mathrm{~km}$. A posttrial feedback session was undertaken to confirm whether the proposed model actually helped the users and eradicate their troubles of boarding in a desired bus. The VIPs will have the chance to get information about bus stop locations.

\subsection{Case study 2}

In this part, the distance is computed between the bus and the VIP by taking the latitude and longitude of the four places like Mandhakarai, Koliyanur, Vallavanur and Madagadipet.

Table 2 shows the locations of the buses which are identified by the proposed model for case study 2 . From the Table 2, it is assumed that, bus is approaching the destination Madagadipet from Villupuram. By taking the latitude and longitude of the four places like Manhakarai, Koliyanur, Vallavanur and Madagadipet, the distance of the bus is computed. The latitude and longitude coordinates of Madagadipet is given by $11.9115^{\circ} \mathrm{N}, 79.6362^{\circ} \mathrm{E}$ respectively. By considering Madagadipet as destination, location details and distance of the bus is sent to the VIP. For illustration, suppose the bus is at Mandhakarai, respective distance is approximately $16 \mathrm{kms}$.

Table 2. Output of the proposed model for case study 2

\begin{tabular}{ccccc}
\hline S.No & Place & Latitude & Longitude & Distance \\
\hline 1 & Mandhakarai & $11.9389 \mathrm{~N}$ & $79.4961 \mathrm{E}$ & $16 \mathrm{~km}$ \\
2 & Koliyanur & $11.9265 \mathrm{~N}$ & $79.5477 \mathrm{E}$ & $10 \mathrm{~km}$ \\
3 & Vallavanur & $11.9207 \mathrm{~N}$ & $79.5800 \mathrm{E}$ & $6 \mathrm{~km}$ \\
\hline
\end{tabular}

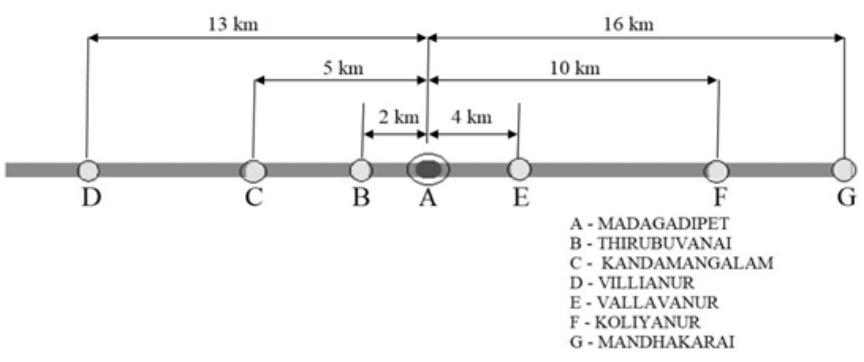

Figure 9. Road map (Layout of the bus routes) between the bus location and destination

Figure 9 represents the road map from Villupuram to Madagadipet (India) and from Puducherry to Madagadipet (India). The point A represents the location of the Madagadipet and point $B$ represents the location of the Thirubuvanai and between A and B the distance is $2 \mathrm{Kms}$. Similarly, for all the locations, respective distances are mentioned in Figure 9. The motivation behind this proposed research work is that buses are fundamental transport means in facilitating VIP to take part completely in the world, right of entry to amenities and services. There are almost 2.2 billion VIPs in the world which is a massive segment of society. In the year 2019, more than a quarter of the world's population suffers from vision impairment released by the WHO.

The proposed model is used to assist the VIPs while boarding the bus. Some of the expected future scopes are, this proposed model can be installed over the private cabs and not just public buses. This proposed model, if manufactured commercially, is very economic and thus can be made available at VIPs or senior citizens, any part of society can make use of it. The VIPs have given the optimistic comments on the proposed method. They said that they board the buses safely with the aid of audio cues which is fitted in the proposed guiding system model. Furthermore, audio playback is vastly helpful for the VIPs to identify their desired bus by providing the information of the desired bus and VIPs preparedness to board. The user can navigate the distance between him/her and the bus. Moreover, it improves their life quality. The proposed 
model helps the VIP to get well-known with expertise in order to turn into more independent on their everyday life is a requirement that everyone should be aware of. Implementation of the GPS and GSM technology is widely used in India, which can be easily implemented in all the buses.

\section{CONCLUSION}

In major cities, buses play an important role in the transportation. VIPs find the difficulty to catch and locate the bus. The proposed model is simple and also turns out to be most effective when it comes to the independence of the VIPs to find the location of the bus. Hence, we have taken the effort to make their lives more comfortable by introducing a system that helps them enjoy transportation services independently and freely like ordinary people, without relying on others. Thus, this proposed method is used to help the VIP and to make them to gain confidence to move around freely. The proposed method has been tested two routes in India. This proposal may be implemented in real time. In the future, the proposed work may be extended. The Digital India initiative ties in well with the Smart Cities Project. Through this initiative, the Government aims to provide the citizens of this country access to the internet, broadband services, egovernance and ensure that information is easily available to the public. Through the high speed to internet facility access, the bus identification system of the VIPs using IOT technology can be implemented. Wi-Fi's connectivity can be established in all the buses. Hence, the VIP can access the multiple buses without any difficulty.

\section{REFERENCES}

[1] https://www.google.co.in/amp/s/medicalxpress.com/ne ws/2017-08-world-population-soar.amp, accessed on 12th August 2019.

[2] Agrawal, S., Anwane, A., Bulankar, P., Thote, D.K. (2014). Bus recognition system for visually impaired persons (VIPs) using RF module. International Conference on Industrial Automation and Computing (ICIAC), Nagpur, India, pp. 45-49.

[3] Quoc, T.P., Kim, M.C., Lee, H.K., Eom, K.H. (2010). Wireless sensor network apply for the blind U-bus system. International Journal of u-and e-Service, Science and Technology, 3(3): 13-24.

[4] Mounika, M.P.S.N., Suma, G., Indraja, D., Babu, E.B., Chinnaiah, M.C. (2015). Bus identification module for visually impaired. International Journal of Engineering and Management Research (IJEMR), 5(2): 452-455.

[5] Aswathy, S., Baby, B.M., Antony, K., Robin, S.M., Er. Raj, A. (2016). Bus identification for blind. Imperial Journal of Interdisciplinary Research (IJIR), 2: 25-29.

[6] Mehra, D., Gupta, D., Vishwarath, T., Shah, N., Chanana, P. Siddharth, Paul, R., Balakrishnan. M., Rao, P.V.M.
(2015). Bus identification system for the visually impaired: Evaluation and learning from pilot trials on public buses in Delhi. 14th International Conference on Mobility and Transport for Elderly and Disabled People, Lisbon, Portugal, pp. 16-24.

[7] El Alamy, L., Lhaddad, S., Maalal, S., Taybi, Y., SalihAlj, Y. (2012). Bus identification system for visually impaired person. Sixth International Conference on Next Generation Mobile Applications, Services and Technologies, Paris, France, pp. 141-144.

[8] Dharini, M., Karpagavalli, C., Lavanya, V., Manikandan, S., Prakash, K.S. (2014). Voice based bus identification system for visually challenged persons. International Journal of Engineering Research and Applications (IJERA), 1: 45-49.

[9] Ding, B., Yuan, H.T., Jiang, L., Zang, X.N. (2007). The research on blind navigation system based on RFID. 2007 International Conference on Wireless Communications, Networking and Mobile Computing, Shanghai, $\mathrm{pp}$. 2058-2061. http://dx.doi.org/10.1109/WICOM.2007.514

[10] Gorantla, S., Rakada, V.B., Attuluri, S., Sirigiri, N.R. (2018). Design and development of an affordable plug in/solar assisted electric auto rickshaw. Modelling, Measurement and Control A, 91(2): 41-47. https://dx.doi.org/10.18280/mmc_a.910202

[11] Pal, P., Pali, L. (2018). Congestion free analysis for emergency vehicles response in Tri-City (PanchkulaChandigarh Mohali) using LTE-A. Modelling, Measurement and Control A, 91(2): 66-72. https://dx.doi.org/10.2139/ssrn.3488230

[12] www.nhc.noaa.gov, accessed on 12th August 2019.

\section{NOMENCLATURE}

ADCs Analog-to-Digital Converters

DACs Digital-to-Analog Converters

GNSS Global Navigation Satellite System

GPS Global Positioning System

GSM Global System for Mobile communication

IC Integrated Circuits

ICSP In-Circuit Serial Programming

IDE Integrated Development Environment

IOT Internet of Things

LCD Liquid Crystal Display

LED Light Emitting Diode

PWM Pulse Width Modulation

RFID Radio Frequency Identification

SIM Subscriber Identity Module

SMS Short Message Service

UART Universal Asynchronous Receiver/Transmitter

USB Universal Serial Bus

VIP Visually Impaired Person

WHO World Health Organization

WSN Wireless Sensor Network 